Review

\title{
Toward an Organizational Theory of Sustainability Vision
}

\section{Sooksan Kantabutra}

Center for Research on Sustainable Leadership and ASEAN Centre for Sustainable Development Studies and Dialogue, College of Management, Mahidol University, Bangkok 10400, Thailand; Sooksan.kan@mahidol.ac.th

Received: 2 December 2019; Accepted: 4 February 2020; Published: 5 February 2020

\begin{abstract}
While vision is considered as the starting point for any transformation process toward sustainability, little is known about how such a vision looks. To fill in a fundamental gap in the corporate sustainability literature, the present study advances a theory of organizational vision into a coherent theory of sustainability vision. It adopts the theory-building approaches of covering-law, enlightenment, and process by comparing and contrasting a diverse set of relevant plausible, logical, empirical, and/or epistemological conjectures so that highlighting occurs to form the substance of the refined theory. The resulting theory of sustainability vision asserts that effective sustainability visions are characterized by the seven attributes of brevity, clarity, future orientation, stability, challenge, abstractness, desirability or ability to inspire and one imagery of stakeholder satisfaction. Relevant propositions and a model are introduced for future research, followed by practical implications.
\end{abstract}

Keywords: corporate sustainability; sustainability theory; sustainability; vision; sustainable business; organizational culture

\section{Introduction}

"Vision" is equated to corporate pitch to convey enduring values and lasting purpose [1] in a pithy and effective way. It guides organizational members to emphasize what really matters to them and their stakeholders [2] in their journey toward transforming vision ideas into action. In addition, formulating a corporate sustainability strategy should follow a sustainability vision [3] in which the focus is not on maximizing short-term wealth or well-being for oneself or a single organization, but for a wide range of stakeholders. The sustainability vision indeed reflects a written announcement of whether corporate leaders are genuinely concerned about strategic sustainability. In essence, sustainability requires the complete integration of social and environmental dimensions into the organizational vision, culture, and operations, indicating that an organizational change and vision are needed as a future destination [4].

In 2009, a behavioral theory of "vision" in organizational settings [5] was introduced to fill in the critical gap among the prevailing vision-based leadership of that time. Although the theory has informed numerous scholars, who have conducted their conceptual, theoretical, and empirical studies in various industrial, organizational, and national settings [6-22], it has not been extended to reflect organizational sustainability, which is, at present, of great interest among scholars and practitioners $[23,24]$.

A decade has passed and the corporate world operates very differently now, a new kind of vision, widely regarded as the starting point for organizational strategy formulation, is required for corporations to sustain their success or even survive and thrive in the long run. The type of organizational vision or a higher-order purpose that induces organizational members simply to do more than they are expected to do is no longer enough. With that in mind, the present study proposes 
to advance the vision theory [5], as it is still concerned very much with maximizing shareholder/owner value alone, which is not conducive to corporate sustainability.

My motivation for the present theory refinement is three-fold. While vision, as part of a strong corporate culture, is considered essential in ensuring corporate sustainability, the "right" vision can push-start the future by marshaling people toward achieving it [25], and the fact that the vision theory [5] was introduced, as discussed earlier, it is not entirely supportive to corporate sustainability.

Second, my literature review indicates that no theory of sustainability vision exists and there are few, if any, reported studies that have investigated the effect of individual vision attributes and content on sustainability performance. Given the scanty theoretical and empirical literature in this specific area, there is also a call from scholars for more theories to inform future development in the corporate sustainability field [24]. Therefore, the present study contributes to this specific area.

Finally, many corporations have had difficulties in incorporating sustainability within the culture and climate of their organization $[26,27]$, the process by which sustainability vision plays a central role because it is core to the culture and climate. As good theory is practical [28], I hope the refined theory of sustainability vision will help to inform corporate practitioners in such an integration.

To address these fundamental gaps in the literature and practice, I attempt to advance the vision theory into a coherent theory of sustainability vision to reflect the current business environment characterized by a non-static, non-linear nature and adamant stakeholder demand. As Kilduff [29] notes that "the route to good theory leads not through gaps in the literature but through an engagement with problems in the world", and scholars should evaluate theories according to their usefulness, as opposed to how true they are $[30,31]$, the resulting sustainability vision theory will help to guide future development of not only theoretical and empirical studies in the field of corporate sustainability, but also corporate sustainability practices.

One should realize that simply having a sustainability vision is not enough to ensure corporate sustainability. To maximize sustainability performance, leaders need to realize their visions through vision communication, organizational alignment, empowerment, and motivation [32]. Since these realization themes are not within the scope of the present theoretical development, I do not discuss them in great length here.

The following sections discuss a theory development approach I adopt for the present study, corporate sustainability definition, vision definition, sustainability vision theory, its associated model, and future research directions. Finally, practical implications of the sustainability vision theory are also discussed.

\section{Theory Building Approach}

Theory building is "the purposeful process or recurring cycle by which coherent descriptions, explanations, and representations of observed or experienced phenomena are generated, verified, and refined" [33]. Effective theory building results in outcome and process knowledge. Outcome knowledge is the knowledge that can explain and predict, while process knowledge is the knowledge that helps to enhance our understanding about what something means and how it works [34]. In the present study, the sustainability vision theory brings about both knowledges. In essence, rigor and relevance should be reflected in good theory and theory building [35], the principle adopted for the present theory refinement.

There is no standard format for developing emergent theory in theory-building research [36], as different theorists have their own choices and preferences. Theory-building research, like any other typical scholarly inquiry, is a method of scholarly inquiry [37-39], as it involves varied and different logics-in-use with a whole set of research worldviews [38]. Theorists apparently come to an agreement that no one superior method to build a theory exists and no one should ever reinforce the use of one [33,35,39-41]. Instead, the theory-building research method should be highly specific, customized, and dictated by the nature of the central theory construction. In my case, it is the sustainability vision theory in organizational settings. Therefore, a pragmatic approach to effective theory building is to 
develop a theory in multiple ways, as deemed appropriate, so that the resulting theory encompasses various perspectives of what a good theory should be, a position I take in advancing Kantabutra's [5] vision theory.

At least three views of what a theory should be exist [42]. First, theory comprises covering laws, suggesting generalizations that, altogether, explain the world as we view, experience, and measure it. Second, theory acts as a platform to enlightenment and a tool of sudden enlightenment. The objective of the theory here is not to generalize, but to clear away stereotypical notions and allow for artful and sensational insights to take place through being a set of groupings and domain assumptions. Third, theory acts as an account of a social process. It focuses on empirical investigations of the plausibility of the prudent, narrative attentiveness to the account's scope conditions. Theory from this perspective demands that hypotheses featuring consistencies in relationships among variables be endorsed by probable accounts of how the forecasted and observed relationships are generated by the actual human actions in the real world. Since theories from this third view are frequently highly intuitive, theorists usually employ diagrams, graphic presentations of data, and/or references as rhetorical devices to elicit epiphanies [42].

Informed by the literature on theory building, I advance the theory of organizational vision [5] into a coherent theory of sustainability vision in organizational settings by integrating the covering-law, enlightenment, and process approaches [42]. Based upon the existing theoretical assertions and empirical evidence, the sustainability vision theory is formulated [43-45]. In the theory building process, a diverse set of plausible, logical, empirical, and/or epistemological conjectures [45] is compared and contrasted so that highlighting occurs [46]. Since theory building is a constantly evolving process, the proposed sustainability vision theory may be refined in the future by theorists who discover new relevant information [47]. Additionally, since theorizing is considered as new proposition development for empirical examination [47], a set of propositions implying research questions and generalizations is generated to direct future research [48]. Finally, a sustainability vision model is derived as a rhetorical device to elicit epiphanies.

Accordingly, the following sections advance the limited knowledge about organizational vision and corporate sustainability by integrating relevant theoretical and conceptual notions and findings into a coherent theory of sustainability vision in organizational settings. The sustainability vision theory attempts to generalize the vision characteristics improving sustainability performance. The refined theory also attempts to serve as a platform for enlightenment about the effect of vision content and each vision attribute on sustainability performance. Finally, it attempts to explain the process by which vision content and each vision attribute positively impacts corporate sustainability. To provide a theoretically informed direction for future research, an initial set of propositions expressing relationships between vision content and seven vision attributes, and corporate sustainability is also generated.

\section{Corporate Sustainability Definition}

Although business responsibilities have been a subject of discussion in the business and society literature, corporate sustainability and corporate social responsibility are not the same matter [49]. Although both suggest creating shared value that offers benefits to society and the environment, two aspects of corporate sustainability prove to be more encompassing than those of corporate social responsibility [49]. Indeed, corporate sustainability suggests the concept of both internally and externally facing accountability and a temporal emphasis incorporating both short-term and long-term sights [49]. Consequently, there is a need to integrate them [49].

In a similar fashion, definitions and main constructs for corporate social responsibility or corporate responsibility and corporate sustainability have grown during the past decades [50], adding to both scholars' and practitioners' confusion, with no clear distinction between the concepts. Notwithstanding the clear importance of corporate sustainability, there is still no commonly agreed upon definition by scholars, which is critical since these different ways that the concept has been defined definitely affect 
the field. In such a context, I adopt the definition by Wilson [51], because it is well grounded in the relevant concepts: sustainable development; corporate social responsibility; stakeholder theory; and corporate accountability theory.

Within the sustainable development concept, three focal areas of environmental, social, and economic outputs are identified. However, the concept does not explain why businesses need to focus on these outputs [51]. Some explanations are offered by the stakeholder theory and the concept of corporate social responsibility. Being aware of the three outputs, businesses meet their moral and business objectives. Finally, the corporation accountability theory asserts that businesses must be held accountable for a broad range of stakeholders by reporting the triple bottom line outputs.

Thus, corporate sustainability is conceptually defined by Wilson [51] as a corporate management set of notions, still acknowledging the business requirement for profitable growth. However, it has much more of an emphasis on balancing among the three domain outputs [52] and publicly reporting them. Thus, I operationally define corporate sustainability as the leadership and management notions that a corporation embraces so that it can deliver social, environmental, and economic outputs at the same time. Since the present study aims to develop a sustainability vision, I use this operational definition to guide my theoretical development.

Building on Wilson's concept, I conceptually define corporate sustainability performance as the triple bottom line outputs of social, environmental, and economic performance [52]. I theorize further that a prudently determined balance among the triple bottom line outputs leads to sustainable wellbeing [53], the ultimate goal of corporate sustainability.

\section{Vision Definition}

My literature review indicates that vision and mental models are related in some complex ways. A mental model is a cognitive psychology term, considered as a conceptual representation of intricate system interactions. Conceptual representations identify the main contributing concepts that provoke action and bring about goal attainment within a system. They articulate causal relationships among the causal concepts along with the variables having effects on their operation [54,55]. Accordingly, these mental models are used to explain and predict actions in a system [56]. They guide and direct organizational members' succeeding actions intended to boost system operations [57]. Two types of mental models exist: normative and prescriptive [57]. A normative mental model describes the system as it is, while a prescriptive mental model describes the system as it ought to be. Essentially, mental models provide a basis for the creation of a vision.

Although the importance of organizational vision is wildly recognized and promoted, vision is still not commonly defined among scholars [5,58]. Considerable disagreement has also continued to prevail over whether and how other equally popular terms, such as mission, core values, corporate philosophy, strategy, and goals, are different from vision [32]. With the definitional confusion, I adapted the approach by Baum et al. [59] to define a vision in the present study as a mental picture of a desired future for an organization each organizational member defines, because it is actually the organizational member's actual vision that guides their choices and actions. Such a definition offers a practical way around the definitional confusion in the vision literature.

Vision is certainly not a small, specific goal, but an overarching one. In comparing vision with goals, Levin [60] suggests that goals identify specific outcomes and convey a commitment toward achieving something that might not exist presently. They outline how when a corporation has chosen to pursue its desired future as vision it is usually translated into specific goals or strategic objectives [61] for management. Goals also offer key indicators to monitor progress toward the desired future. Really, they are not that desired future that vision is. The aspiration and commitment for the future is what most likely confuses goals with vision.

In more sustainable corporations, vision typically emerges from organizational members [62]. Indeed, vision is developed when the organization as a whole engages in a collaborative process [63-65]. 
In this context, communication during vision formation is central to vision assimilation and the creation of the shared vision owned by organization members.

It is well recognized that vision needs to be shared by organizational members to create an impact on organizational performance [66]. Shared vision has the force to connect and commit organizational members one to another and to the new future they are bound to create [67]. It is this shared vision that enables corporations to overcome the difficulties they have experienced in embedding sustainability into their strategy, organizational culture and climate, and operations. When organizational members truly share a vision, they are linked, destined together by a common ambition. Personal visions derive their influence from an individual's profound caring for the vision, and a shared vision collectively derives its influence from a common caring. In fact, a reason people seek to build a shared vision is their desire to be connected in an important undertaking [67]. Therefore, when they realize they are connected to a success, they are even more satisfied, more emotionally committed to, and more widely share the vision. Moreover, satisfied results, such as customer and stakeholder satisfaction, also motivate organizational members and raise the intrinsic value of effort [68]. This virtuous spiral benefits the organization, where the behavior of organizational members aligns with the vision.

Shared vision among members of an organization is not an end goal in and of itself [66]. Rather, it facilitates common goals, perspectives, and outcomes [66]. The function of shared vision as a facilitator, as opposed to an end goal, is critical since empirically, organizations have been found to be goal-seeking rather than goal-realizing systems, meaning that they constantly seek and change goals $[69,70]$. Endorsing this view, the literature on corporate sustainability [71,72] has provided convincing evidence that sustainable corporations are characterized by a widely shared corporate culture. They are often leaderful with self-leading, self-managing members sharing an organizational vision and values, allowing them to effectively respond to the fast-changing and increasingly complex business environment [73] as their organizational members espouse the shared vision to guide daily operations and decision-making, specifically when tradeoffs among goals are necessary.

A vision must be articulated to continuously link the needs and values of organizational members at present and in the future with a collective vision [74,75] and mobilize them to pursue it [76,77]. A vision must be communicated among organizational members, through written statements and personal communication [78]. Visions are usually documented and communicated predominantly in the traditional form of concise vision statements [79]. O'Connell et al. [18] agreed with the notion of having a vision statement, by stating that "although visions might exist without ever being formally codified, in practice, they need to be made explicit". A vision statement allows organizational members to discuss, debate, accept, or even reject [80].

Endorsing this view, sustainable corporations manage their corporate culture via the statements of vision and values, designed to communicate core beliefs and unwritten rules [71]. They take more time to communicate a vision to enable vision effects. Always, a great culture starts with a vision statement [81]. as it can assist in orienting organizational members and stakeholders when it is genuine and displayed prominently [81]. A strong organizational culture turns sustainable corporations into a "special place to work" [71]. The "specialness" varies significantly from one corporation to another, given the details of each individual organization's philosophy, vision, and values. These corporations do not need to mold the organizational members to attain a common vision because they continuously recruit and retain people who already share the vision and core values. Therefore, at any given time, the vision and core values are already widely shared.

However, the prevailing corporate approach of maximizing short-term shareholder value with a high staff turnover rate does not allow organizational members time to integrate their own values with those of the organization [82]. It does not communicate consistent values to the members either [82]. Therefore, developing a strong corporate culture is highly challenging, if not impossible, where turnover rate is high, and no alignment between individual and organizational vision and values exists. Such unalignment among the prevailing, less sustainable organizations can possibly explain the fact that sustainability goals or values can have only a moderate impact [83] and that 
organizational goals and ends are frequently decoupled from the actual organizational practices [84], typically called "decoupling". Decoupling is indeed concerned with the implementation of goals and policies $[84,85]$. To reduce the gap between goals and practices, a development of vision-critical goals and policies that fit corporate values, culture, and context, and publicly stating the goals and policies will help [86]. Moreover, relevant measures are to be identified to help monitor the implementation of the goals and policies and assess the impact [86]. Lastly, publicly reporting of the impact will foster transparency and stimulate the companies to narrow the gap between the goals and policies, and the actual practices [86]. With consistent acts, sustainable organizations are organizations of integrity, where words are essentially translated into action [71,72].

The literature review has indicated the need for an organization hoping to sustain itself to have a vision statement as a tool to communicate and facilitate the vision-sharing process among organizational members. Clearly, this vision statement must reflect the mental picture of a desired future for the organization or vision; that is, developing a vision statement encompassing the mental picture of a desired future of the organization is highly challenging. In the present study, I attempt to propose a sustainability vision theory that introduces characteristics of such a vision statement.

\section{Sustainability Vision Theory}

This section introduces a proposed theory of sustainability vision. In general, it addresses characteristics of a theoretically effective vision statement, meaning it represents a mental picture of a desired future for an organization, and helps to facilitate that picture-sharing process within an organization and among stakeholders. Therefore, "vision" from here on refers to a vision statement.

Unlike the vision theory [5] introduced in 2009, which addressed only vision attributes, I assert that effective sustainability visions be composed of two components: vision content and attributes. While vision attributes are associated with such vision characteristics as conciseness, abstractness, challenge, clarity, inspiring, stability, and future orientation, vision content is more associated with the palpable content of vision [32,59]. To determine if a vision is positive or negative, vision attributes together with vision content are to be considered, particularly given the corporate sustainability context in which corporate stakeholders play an important role. Endorsing this view, Senge [67] argues that positive and negative visions exist. While negative visions support the status quo, positive visions direct to real change for the better [67].

Negative visions divert energy that can be put into innovation into prevention, signal that the organization pulls together only when threatened, and are unavoidably short-term [67]. These visions limit corporate prosperity and are detrimental to corporate sustainability. Alarmingly, negative visions are more commonly founded in the work place than positive ones.

Positive visions are inspirational, infused with desirable, often sustainability, values, and transparent in their approach in attaining a better and desirable future [67]. Certainly, these visions are more effective than negative ones with no emotional appeal [18]. Therefore, positive visions possess the integrity to spur change. The notion of positive visions is one that is supportive to corporate sustainability, as it promotes consistent acts and continuing development required to respond to the fast-changing and increasingly complex business world.

In the following sections, I introduce vision content and attributes necessary for ensuring corporate sustainability. In other words, they describe how a "positive" vision looks.

\subsection{Vision Content}

Vision attributes alone are unlikely to affect business and sustainability performance positively. With vision attributes, vision content is needed to express and clarify central organizational values that combine a desirable manifestation of its direction together with a concrete prescription for achieving its audacious goals [87-89]. It also defines the identity of each individual organization [87-89].

In the corporate sustainability context, these central organizational values reflected in the vision or corporate mental model are frequently about a variety of virtues (e.g., perseverance, ethics, and 
integrity), social and environmental responsibility, and innovation for stakeholders [90,91]. I also argue that, for a corporation to succeed and thrive in the future, its vision needs to contain reference to sustainability [92]. In essence, visions that seem inspiring [93,94] are ones that relate the potentials and growth contained in them to organizational values [95-97]. These inspiring visions make the values definitely clear among organizational members [95-97]. In effect, a clear and inspiring vision widens a corporate support base by shimmering the stakeholders' needs and aspiration, transcending differences of individuals, and attracting a wide range of stakeholders to share concerns about the organization's future [25].

Therefore, vision content, or "vision imagery", is critical to the future of the organization. To determine vision effectiveness, one must realize that not all visions create a positive impact on attitudes of organizational members, and a differentiation between "strong" and "weak" visions is needed [98]. In theory, vision content may focus on any shared ideas about anything to form the central driving image [99]. Empirically, vision content needs to be considered because findings indicate that vision imagery affects organizational performance $[59,100,101]$.

Despite relatively scanty research into vision content, a successful strategic vision takes into account such strategically essential aspects as industry, clients, and the industry's specific competitive environment [102]. Many corporate leaders feel uneasy to conclude how they arrived at their vision [25]. Some claim to have arrived at their vision mysteriously, because such a revelation occurs only to a mind that has already accumulated a great deal of wisdom and understanding about a particular organization, and that has been ruminating deeply, unconsciously, about future directions of the organization [25]. Given that kind of context, corporate leaders, therefore, need to know their organization intimately to arrive at a meaningful vision, because their unique experience and intuition about the organization can help them synthesize information they have gathered in formulating a corporate vision [103]. It is this unique intuition and experience reflected in the content of their vision that potentially make it difficult to define common vision content across various organizations.

However, in the corporate sustainability context, I argue that a broad guideline on what constitutes vision content that leads to sustainable development is required to ensure that corporations meet the needs of current and future generations, since sustainable development is defined as "development that meets the needs of current generations without compromising the ability of future generations to meet their needs and aspirations" [104]. In response to the quest around the world for a holistic approach to corporate sustainability, a behavioral theory of corporate sustainability [73] was proposed, providing some clue on how sustainability vision content should look, so that corporate sustainability and sustainable development are ascertained.

Built upon the seven established theories of self-determination [105], stakeholder theory [106], sustainable leadership [71], complexity [107], knowledge-based [108], dynamic capabilities [109-111], knowledge management [112], and an emerging theory of sufficiency economy in business [91], the theory of corporate sustainability [73] asserts that corporations adopting the sustainability practices of perseverance, resilience, moderation, geosocial development, and sharing are sustainable. Each is introduced in more detail below.

Perseverance suggests that corporations whose members persevere to improve processes, products, and services for their stakeholders enhance their own corporate sustainability prospect. In relation to resilience, resilient corporations that always anticipate and prepare for change enhance their own corporate sustainability prospect [73]. Prudent decision-making is theorized to improve corporate sustainability prospect by taking into consideration consequences of such decision-making on a broad range of stakeholders at all levels of a business organization [73].

According to the corporate sustainability theory [73], business corporations that are moderate do not aim at maximizing short-term profitability, but try to balance between short-term and long-term profitability. It is this long-term view that enables corporations to outperform competitors focusing on short-term goals. It allows corporate leaders to prudently manage all aspects of their corporation, including strategy, work processes, and stakeholder relationships. The process of careful and reasonable 
decision-making involving the consideration of short-term and long-term consequences on stakeholders enhances corporate sustainability prospect.

In relation to geosocial development, in theory, business organizations investing now in taking care of their stakeholders and integrating social and environmental responsibility with their entire operation enhance their own corporate sustainability prospect [73]. Corporations that take into account a broad range of stakeholders by focusing their efforts and resources on delivering relevant values to them strengthen their business and societal relationships to ensure sustainable profitability and survival. Additionally, according to the financial and social achievement of their organization, leaders valuing the breadth of corporate stakeholders appear to achieve higher leadership positions [113].

Lastly, theoretically, sharing knowledge internally among organizational members and externally with corporate stakeholders, including competitors, heightens corporate sustainability prospect [73]. Knowledge-sharing is required for a sustainable corporation, and it typically leads to corporate incremental and radical innovation. At times, corporations need revolutionary thinking from corporate members and stakeholders to achieve innovation in products and services. Innovation is achieved when a corporation executes its strategies that integrate sustainability within them to align the triple bottom line value for future generations.

The knowledge-sharing practice is also endorsed by the corporate sustainability strategy of coopetition, whereby competitors concurrently cooperate with each other to secure mutual benefits [114-116]. In today's corporate world, information exchange between competing corporations is regarded as a way through which corporations cooperate to improve overall performance for all competing corporations via coopetition [117]. Prudent coopetition brings about many benefits, including lower costs and risks, decreased uncertainties in relation to production innovation, and rapid increase in production efficiency $[116,118]$. From an organizational vision point of view, coopetition suggests a new way to perceive competitors-not as opponents, but proponents.

Noticeably, all of the five practices core to the corporate sustainability theory [73] focus on balancing the demand among a broad range of stakeholders by satisfying their various needs. Stakeholders are anyone who is affected or will be affected directly or indirectly by a business' operation, including competitors, the society, the environment, and even future generations. This notion is supported by the stakeholder theory, which provides the kind of attitudes and organizational practices for the corporation to survive, despite difficult times, and to prosper in the long run [119]. The influence of a broad range of stakeholders in corporate strategy dictates responses on behalf of the corporation, as it reflects the possibly threatening or cooperating power of each stakeholder within a context of mutual interests.

In the corporate sustainability context, corporations adopting the stakeholder theory approach try to satisfy various demands of a wide range of stakeholders by balancing the demands among them. Such a prudently determined balance in turn enhances long-term stakeholder relationships that support the corporations in ensuring long-term, sustainable success.

In addition, corporate sustainability theorist Ketprapakorn [24] has formulated an Asian Sustainable Supply Chain Management model indicating that, to ensure the sustainability of their operations, corporations must develop a shared sustainable supply chain vision between a corporation and its stakeholders. In Asia, external stakeholder forces, such as governmental policies, industrial policies, and environmental regulations from developed nations, play an important role in ensuring corporate sustainability. Furthermore, supportive sustainable supply chain strategies are needed to turn the vision into reality. To support the operations, eco-innovation practices, comprising eco-friendly technologies and talent selection to support innovation and sustainable production indicators to monitor progress toward corporate sustainability, are considered integral. Ketprapakorn [24] predicates that the shared sustainable supply chain vision taking into account such stakeholders is required as part of corporate supply chain management to ensure corporate sustainability. Theoretically, a shared vision containing imagery about satisfying a wide range of stakeholders enables the sustainable supply chain to function. 
Ideally, sustainability vision should contain imagery about increasing the satisfaction of a wide range of stakeholders, since they are critical to sustainable corporate success. However, extant research has shown that it is impossible to satisfy every stakeholder with a unified vision, which is why several research streams have developed such concepts as organizational polyphony, pluralism, hypocrisy, and hybridity in response to contradicting demands among a wide range of stakeholders [120-122]. Since corporate sustainability in the present study is defined as the leadership and management approach that a corporation adopts so that it can concurrently deliver social, environmental, and economic outputs, the range of stakeholders is narrowed down to ones clearly relevant to this definition and can be satisfied. From here on, stakeholders in the present study are defined as shareholders/owners, organizational members, customers, the society, and the environment.

Therefore, I argue that sustainability vision content contains imagery about increasing stakeholder satisfaction as venture growth, customer, and staff satisfaction imageries were significantly associated with improved venture growth, customer, and staff satisfaction, respectively, in previous studies $[59,101]$. In a similar fashion, I argue that the more imagery about satisfying stakeholders contained in a vision, the better the corporate sustainability prospect. Accordingly, the following proposition was formed for the relationship between vision content of stakeholder satisfaction imagery and sustainability performance.

Proposition 1: visions containing reference to increasing the satisfaction of stakeholders increase corporate sustainability performance.

\subsection{Vision Attributes}

Despite the fact that vision is defined differently, many scholars seem to agree with Senge [67] by suggesting "positive" vision attributes. Given a wide variety of suggested attributes for positive vision, Kantabutra [5] derived from the theoretical and empirical literature seven commonly shared attributes: brevity, clarity, future orientation, stability, challenge, abstractness, desirability or ability to inspire (see Table 1 for definitions). These seven attributes in combination create effects on performance. Brevity means the extent to which a vision contains approximately 11-22 words, while clarity means the extent to which a vision can be made clear in approximately 5 minutes by pointing directly at an overarching goal. This overarching goal is most critical as it is connected to the other six vision attributes. Brevity and clarity are related, because pointing directly at an overarching goal suggests a brief vision statement. Abstractness means the extent to which a vision is not a one-time, specific goal that can be achieved, and then the vision is abandoned. Vision abstractness is generally connected to vision clarity, as a clear vision points directly at an overarching or "big" goal, which is not a one-time, specific goal that can be met, and then discarded.

Table 1. Vision attribute definitions.

\begin{tabular}{|c|c|c|}
\hline No. & Vision Attribute & Definition \\
\hline 1 & Brevity & The extent to which a vision contains approximately $11-22$ words. \\
\hline 2 & Clarity & $\begin{array}{l}\text { The extent to which a vision can be made clear in approximately } 5 \\
\text { minutes by pointing directly at an overarching goal. }\end{array}$ \\
\hline 3 & Abstractness & $\begin{array}{l}\text { The extent to which a vision is not a one-time, specific goal that can be } \\
\text { achieved, and then the vision is abandoned. }\end{array}$ \\
\hline 4 & Challenge & $\begin{array}{l}\text { The extent to which a vision challenges organizational members to } \\
\text { persist with trying their best to deliver desirable outcomes. }\end{array}$ \\
\hline 5 & Future orientation & $\begin{array}{l}\text { The extent to which a vision points toward the long-term perspective of } \\
\text { an organization. }\end{array}$ \\
\hline 6 & Stability & $\begin{array}{c}\text { The extent to which a vision is unlikely to be affected by any } \\
\text { environmental change. }\end{array}$ \\
\hline 7 & $\begin{array}{l}\text { Desirability or } \\
\text { ability to inspire }\end{array}$ & $\begin{array}{c}\text { The extent to which a vision declares an overarching goal that directly } \\
\text { appeals to organizational members. }\end{array}$ \\
\hline
\end{tabular}

Challenge means the extent to which a future picture of an organization intrinsically motivates organizational members to persist with trying their best to deliver desirable outcomes by showing 
a realistic degree of discrepancy between the present and the envisioned future. Vision challenge is generally connected to vision clarity, as pointing directly at an overarching goal suggests the future picture of an organization.

Future orientation means the degree to which a sustainability vision points toward the long-term perspective of an organization. Vision challenge is generally connected to vision future orientation, since the envisioned future is indeed the long-term perspective of an organization. Vision future orientation is generally connected to vision clarity, as pointing directly at an overarching goal suggests the future.

Stability means the extent to which the future picture of an organization is unlikely to be affected by any environmental change. Vision stability is generally connected to vision clarity and future orientation, as pointing directly at an overarching goal suggests the future picture of an organization.

Desirability or ability to inspire refers to the extent to which a vision declares an overaching goal that directly appeals to organizational members. Vision desirability or ability to inspire is generally connected to vision clarity, as a clear vision points directly at an overarching goal.

As discussed above, these seven attributes interact to facilitate the vision communication and sharing process among organizational members so that each member espouses the same vision [32]. Each one of the attributes alone does not create an impact on organizational performance. The resulting shared vision enables their organization to become self-adapting [123], which is required to survive and thrive in the increasingly complex corporate environment.

Built upon the vision theory [5], the theoretical process by which each vision attribute, interacting with the other six vision attributes and the vision content of stakeholder satisfaction imagery, positively affects corporate sustainability performance initially through vision communication, shared vision, and emotionally committed organizational members is explained below. Relevant propositions were derived accordingly.

\subsubsection{Vision Brevity}

It is asserted that effective sustainability visions are brief. Brevity means the extent to which a sustainability vision contains approximately 11-22 words, the length empirically found to make a significant impact [32]. Certainly, organizational members understand a concise vision message faster than a long one [124], since a concise vision permits considerable, recurrent communication required to turn a sustainability vision into reality $[125,126]$. Organizational members at all levels need to receive sustainability vision messages as often as possible to offer support so that corporate sustainability initiatives are successfully implemented [127].

When organizational members listen to another member speaking about sustainability vision briefly, they can grasp the message instantly, permitting them to use the concise vision to inform their daily decision-making and operations immediately. Vision guiding enhances the satisfaction of organizational members [32]. Sharing the sustainability vision, organizational members are not confused and do not get lost on their journey toward satisfying stakeholders, as reflected in the vision content. In the process, they satisfy themselves, leading to satisfied customers [128] and other stakeholders [73,91], given the stakeholder satisfaction imagery.

Speaking about concise messages is regarded as most important for effective organizational members who get the right thing done [124]. When organizational members are continuously and frequently reminded of the sustainability vision messages, and genuinely desire to actualize the sustainability vision, they do their best within and beyond their roles and duties to make corporate sustainability a reality $[125,126]$.

Therefore, the following proposition was advanced for the relationship between vision attribute of brevity and corporate sustainability performance.

Proposition 2: taking into account the other six attributes and content, sustainability visions that contain approximately 11-22 words improve corporate sustainability performance. 


\subsubsection{Vision Clarity}

Understandably, brevity alone is not enough, the vision must also be clear. Theoretically, clear sustainability visions are more effective than unclear ones [5], supported by numerous organizational communication scholars $[127,129,130]$ who believe that a message must be clear and communicated clearly to get the right thing done in an organization. Consequently, organizational efficiency and effectiveness are enhanced by getting the right thing done. I argue that a sustainability vision as a message among organizational members must be clear. Clarity means the extent to which a vision can be made clear in approximately five minutes [32,125]. With stakeholder satisfaction imagery, a clear sustainability vision of what an organization could be in the future assists organizational members to set priorities of the organization, because they understand the organizational purpose and objectives [126]. Specifically, I argue that a sustainability vision should be clear about the priorities of stakeholders. I also theorize further that an effective sustainability vision is unambiguous, so that it can inform subsequent sustainability strategy formulation and actions effectively, and be internalized by organizational members whose determinations are essential in realizing the sustainability vision [25].

With concise messages, clear messages are regarded as most important for effective organizational members [124], given the fact that organizational members can then perform what they need to perform. Most significantly, unclear visions were quoted as a major cause of declining corporate effectiveness in the 1970s and 1980s [131]. The positive relationship between vision clarity and corporate effectiveness was also reported elsewhere [132]. Essentially, clear articulation of sustainability vision crystallizes in the mind of organizational members what is desired [91,133], developing vivid images in their heads to inform what and how to foster corporate sustainability. Such vision articulation, therefore, equips organizational members with a common direction in espousing the sustainability vision to inform their daily decision-making and operations, particularly those affecting stakeholders.

In the corporate sustainability context, clarity is particularly important, as the theory of corporate sustainability [73] asserts that pursuing goals relevant to individual growth, relationships, society, and health brings about greater satisfaction of psychological wellbeing than pursuing other goals relevant to wealth, recognition, and image. In fact, pursuing these latter goals emasculates the prospect of sustainable wellbeing [73]. Therefore, a sustainability vision as the overarching goal should be sufficiently clear about these aspects so that organizational members can decide whether to pursue the vision wholeheartedly. Once they decide to pursue the sustainability vision unreservedly, they experience the self-endorsement of their actions, leading to improved persistence, performance, social functioning, and physical and psychological wellbeing [91,134], which I argue leads to corporate perseverance needed to endure and survive difficult times [73].

A clear vision also affects affective commitment and subsequent enrolment of organizational members [91,133]. It is well known that realizing a vision requires the emotional commitment and enrolment of organizational members [32,91]. These two prospects are enhanced with a clear vision and its compelling articulation [133], since the compelling articulation of a clear vision touches and moves organizational members from a stage of resistance to that of genuine compliance. To reach the stage of genuine compliance, both affective commitment and enrolment of organizational members are required [135]. By taking action that they request and initiate to realize the sustainability vision's aims in order for themselves to be enrolled in the sustainability vision, organizational members pulled to the sustainability vision need to espouse its innate values [133]. Once enrolled, these organizational members willingly do whatever possible to carry out the sustainability vision within sound reason.

Additionally, a sustainability vision must point directly at an overarching goal to be clear in approximately five minutes [5], since goal-setting has been the focus of organizational performance studies at all organizational levels [91,136]. In field research, goal-setting was reported to render significant, positive effects on firm productivity after researchers examined the role of goal-setting in corporate planning, processes, strategy, and performance [137]. In addition, by knowing the sustainability vision and policies of the organization reflecting organizational goals [130], organizational 
members are equipped with a clear idea of what their organization values and what it is about [91], accentuating the need for clarity in the sustainability vision.

Accordingly, the following proposition was formed for the relationship between the vision attribute of clarity and corporate sustainability performance.

Proposition 3: taking into account the other six attributes and content, sustainability visions that directly point at an overarching goal they want to achieve improve corporate sustainability performance.

\subsubsection{Vision Abstractness}

In addition to clarity and brevity, effective sustainability visions are abstract [5] in order to create a significant impact on sustainability performance. Abstractness means the extent to which a vision is not a one-time, specific goal that can be achieved, and then the vision is abandoned [5,32]. Lending support to this perspective, vagueness implies a longer-lasting organization with a long-lasting purpose, both inspiring organizational members [138]. In terms of organizational effectiveness, abstract visions also prevent a too specific group boundary [139], which often leads to too many groups to manage and organizational conflicts. Empirically, categorization along one dimension is enough for effective group formation in an organization [140]. Lending support is also the initial observation that the acknowledgement of the possession of a single substance and the identification of merely one single common trait could effectively help form a group, and more dimensions are often one too many [141]. In particular, ensuring corporate sustainability requires a coherent organization.

Moreover, the theory of corporate sustainability [73] asserts that self-managing and self-leading individuals at all organizational levels are needed in the present complex corporate world, while maintaining the overall organizational coherence. Certainly, abstractness helps to achieve this coherence, as it is inclusive of all organizational interests. This inclusiveness allows organizational members to individually, creatively interpret the sustainability vision in their own way $[73,139]$, particularly supportive when sustainable enterprises are reported to have innovation as their core value [71]. The individually creative interpretation among them is especially necessary when they are allowed substantial independence and judgement in their work decision, and use the sustainability vision to inform their decision-making and actions [73], suitable for the non-static, non-linear nature of the present corporate world. As business organizations are multifaceted and adaptive systems, human organizations need to be able to emerge and re-emerge, organize and re-organize themselves, and adapt and re-adapt when they encounter disequilibrium and chaos [73]. In this context, substantial independence and judgement in the work of organizational members are required, as they have been reported as fundamental in built-to-last organizations [142].

To demonstrate the necessary role of abstractness, "to be the leading socially friendly retailer in Thailand" suggests that there are at least two groups in an organization. Any organizational members who share this future picture are emotionally part of the retailer, while those members who do not share are not. This vision is abstract enough to imply categorization along only one dimension. The abstract vision also suggests the creation of group formation to realize it. The retailer's vision could really mean anything according to the individual interpretations among organizational members, as it is adequately vague, allowing organizational members from different functions to use their imaginative and creative interpretations to favor themselves, enabling the sustainability vision to be appealing to all. Therefore, the sustainability vision is theoretically inclusive to all organizational members' interests, particularly when the sustainability vision contains stakeholder satisfaction imagery that suggests increasing the satisfaction of stakeholders.

Accordingly, the following proposition was formed for the relationship between vision attribute of abstractness and corporate sustainability performance.

Proposition 4: Taking into account the other six attributes and content, sustainability visions that are not a one-time, specific goal that can be met, then abandoned, improve corporate sustainability performance. 


\subsubsection{Vision Challenge}

Challenge characterizes effective sustainability visions, in addition to brevity, clarity, and abstractness [5]. Challenge refers to the extent to which a sustainability vision intrinsically motivates organizational members to persist with trying their best to deliver desirable sustainability outcomes $[32,91,103]$. The greater the discrepancy between the future desired picture and the present status quo, the more likely is the attribution that the organizational members have a remarkable sustainability vision $[91,143]$, the more likely organizational members are to give credit to the remarkable sustainability vision $[91,144]$, and the more challenging is the sustainability vision. Therefore, the involvement of organizational members is critical for determining the degree of challenge in the vision.

Supporting this view, Collins and Porras [26] observed that visionary corporations in their study deliberately set themselves "big", audacious, and risky goals, many of which "bet the company" [145]. With these highly risky goals, the whole corporations were forced upon great challenge, putting them in an unavoidable position to reinforce their market leadership. This is understandable, since greater difficulty leads to higher organizational performance [146]. With a very discrepant and idealized vision, organizational members are equipped with a vision that suggests a sense of great difficulty and challenge. Really, they are provided with a motivating power for change [91,144], since an extreme discrepant position within the scope of acceptance allows organizational members to feel the greatest pressure to change their attitudes $[147,148]$. Given that vision symbolizes organizational hopes, dreams, and aspirations, it is likely to be within the scope of acceptance, regardless of the risky discrepancy.

Clearly, challenging sustainability vision is a form of intrinsic motivation. The theory of corporate sustainability [73] asserts that the perseverant behavior of corporate members who persist to carry out what needs to be done, despite great difficulties and influence from other people or situations, is key to long-term, sustainable success. Being challenged by a sustainability vision, self-motivated individuals always find self-endorsement to continue a difficult task, without requiring extrinsic motivator. They can do so because they share a vision of their organization, including the vision content of stakeholder satisfaction imagery. With the shared vision and purpose, they therefore are always intrinsically motivated to carry on. Such continuing, intrinsic motivation in human beings leads to corporate perseverance behavior, in turn enhancing corporate sustainability [73]. This emphasizes the importance of challenge in a sustainability vision.

Indeed, effective sustainability visions are challenging by showing a realistic degree of discrepancy between the present and the envisioned future. With such a challenging vision, intrinsically motivated organizational members persist with doing their best within their roles and duties to achieve desirable sustainability performance [73]. It is human nature that organizational members improve their self-esteem in their challenging journey toward attaining the sustainability vision [149], which in turn satisfies themselves [150]. When motivated organizational members with the vision content of stakeholder satisfaction imagery are satisfied, customers [128] and stakeholders [73] are also satisfied, enhancing corporate sustainability performance in various ways.

Therefore, the following proposition was developed for the relationship between the vision attribute of challenge and corporate sustainability performance.

Proposition 5: taking into account the other six vision attributes and content, sustainability visions that challenge organizational members to persist with trying their best to deliver desirable sustainability outcomes improve corporate sustainability performance.

\subsubsection{Vision Future Orientation}

In addition to brevity, clarity, abstractness, and challenge, future orientation characterizes effective sustainability visions [5]. Future orientation means the extent to which a sustainability vision points toward the long-term perspective of an organization [32,103]. Since the purpose of the visionary process is to progress from the present status quo to a new, desired future state, vision is always about a desirable future $[5,32,151]$. Really, a future image of the organization is required to allow for "creative tension" around the gap between the sustainability vision and the present reality [67]. This creative tension 
permits organizational members to create a fundamental shift toward the sustainability vision. This tension pulls organizational members from where they are currently toward the sustainability vision.

Underlining the notion of future-oriented sustainability vision, effective organizational members who take a leadership role have a desirable vision, painting a possible future for their organization [131]. A sustainability vision has the power to enthuse organizational members or entice their commitment only when it allows them to sense a view of the clearly better future for the organization, themselves, and/or the society [25]. Moreover, since sustainability visions are seen only as the starting point of a lengthy, evolving, transformational journey $[25,126,131]$, effective sustainability visions should theoretically contain the long-term view of an organization.

Accentuating the need for future-oriented sustainability vision, the corporate sustainability theory [73] asserts that a long-term perspective is integral to ensuring corporate sustainability, as sustainability is clearly a long-term matter. In sustainable corporations, organizational members taking a long-term view are held accountable for the short-term and long-term consequences of their decisions and actions [73]. With a future-oriented sustainability vision, they are allowed for long-term strategy formulation and the avoidance of "short-termism" that has caused a great number of corporate bankruptcies globally [24,71]. They are reinforced to do so via a design of compensation and incentive schemes, which takes into consideration the long-term corporate performance, supported by the future-oriented sustainability vision.

In theory, the future-oriented sustainability vision promotes the process of careful, reasonable decision-making that involves considering long-term and short-term consequences on the corporation and its stakeholders [73]. Future orientation in the sustainability vision also reinforces prudent management of operational and policy risks and available opportunities, making the corporation less prone to the impact of ad hoc hostile events [73].

The following proposition was developed accordingly for the relationship between vision attribute of future orientation and corporate sustainability performance.

Proposition 6: taking into account the other six vision attributes and content, sustainability visions that indicate the long-term perspective of an organization improve corporate sustainability performance.

\subsubsection{Vision Stability}

Effective sustainability visions are stable, in addition to being brief, clear, abstract, challenging, and future-oriented. Stability means the extent to which a sustainability vision is unlikely to be affected by any environmental change [5], implying a careful sustainability vision development in a highly unpredictable business environment. Stable visions do not shift in response to short-term trends, technology, or market changes. Theoretically, an effective sustainability vision is stable, since it means to inform organizational members over time. Being stable, they must also be sufficiently flexible to weather fluctuations. Only minor changes are to be made to a sustainability vision to reflect changes in the surrounding environment [152]. An effective sustainability vision represents a general idea that does not change significantly over time [5], as a vision that changes significantly over time negatively impacts corporate-wide implementation of an existing vision. It is well recognized that a vision is the basis for corporate planning and implementation [131,153]. With an unstable vision, on-going activities toward realizing the existing vision would be suspended, increasing unnecessary costs. Importantly, an unstable sustainability vision confuses organizational members as they are executing sustainability strategies, eventually leading to their declining commitment to the vision and corporate sustainability performance.

Furthermore, an unstable sustainability vision as a management tool suggests a lack of integrity $[103,154]$. Outstanding individuals having once taken a position do not "flip-flop" on positions $[155,156]$. Instead, they stand firm. Effective organizational members are consistently credible and exceptionally trustworthy $[157,158]$. In the corporate sustainability context, effective organizational members should be perceived as credible and trustworthy among themselves and by other corporate stakeholders [73-91]. Integrity as reflected in the sustainability vision is, therefore, 
critical to corporate sustainability, given that organizational members and corporate stakeholders sense very soon whether one really stands behind their sustainability vision with their mind, heart, and soul [151]. With an unstable sustainability vision, corporate integrity is certainly questioned by organizational members and stakeholders. The moment organizational members and stakeholders start questioning the seriousness of realizing the sustainability vision, skepticism is always the result [151], causing deteriorating sustainability performance.

As a strategic tool, once a sustainability vision is formulated, strategy and strategic goals at all levels must be derived accordingly. Clearly communicating established goals among organizational members and measuring them is critical to successfully implementing sustainability initiatives [159]. Quinn and Dalton [160] believe that, "having sustainability goals and objectives encourages employees to incorporate sustainability into their day-to-day activities". Therefore, sustainability goals at the level of individual organizational members are necessary for a successful implementation of sustainability initiatives [161]. The individual performance development and evaluation plans of organizational members should include these sustainability goals [161]. If the sustainability vision is not stable, strategic goals at all levels are certainly affected, leading to confusion and dissatisfaction among organizational members, and unsatisfactory corporate sustainability performance. Therefore, stability in sustainability visions is theoretically integral to ensuring corporate sustainability.

The following proposition was developed for the relationship between vision attribute of stability and sustainability performance.

Proposition 7: taking into the other six attributes and content, sustainability visions that are unlikely to be affected by environmental change improve corporate sustainability performance.

\subsubsection{Vision Desirability or Ability to Inspire}

Together with the other six attributes, desirability or ability to inspire characterizes effective sustainability visions, as a vision is used to persuade organizational members to work toward a common goal [103]. At least, it must be desirable or inspiring. Desirability or ability to inspire refers to the extent to which a vision declares an overarching goal that directly appeals to organizational members [5]. Management researchers have long agreed that desirability or ability to inspire is important to attract organizational members, asserting that it draws on organizational values and culture to be alluring [91,162]. Theoretically, effective sustainability visions contain promises related to organizational values [91]. They make these values absolutely clear to all stakeholders [73,95-97]. It is these promises and organizational values that make the sustainability visions appear desirable or inspiring [93,94].

Given their desirability or ability to inspire, effective sustainability visions widen a support base by allowing organizational members to reflect on the needs, hopes, dreams, and aspirations of many corporate stakeholders. The desirable sustainability visions also transcend individual differences and draw a wide range of stakeholders into a society of concerns about the organization's future [25], essentially true when the sustainability visions contain reference to increasing stakeholder satisfaction.

Generally, intrinsic motivation, hopes, dreams, and aspirations suggest a clear sense of personal growth, belonging, societal contribution, and health [163]. Sharing a desirable sustainability vision, intrinsically motivated organizational members are invigorated by the enjoyment of the activity they do, as opposed to focusing on the end results [73]. Corporate sustainability theorists Ketprapakorn and Kantabutra [90] would agree with this assertion, as they promote an alignment between corporate values and values of individual organizational members as a means to nurture on-going intrinsic motivation, therefore ensuring corporate sustainability.

Effective sustainability visions therefore meet the hopes, dreams, and desires of organizational members [71]. Great power from the inspiring sustainability vision and affective engagement to the sustainability vision among organizational members takes place in sustainable corporations [72]. Self-motivating organizational members are excited, given their attraction to the sustainability vision, sharing the organizational values, and consequently sensing the meaningfulness and importance of 
their work [71]. In addition, organizational members need to know why their jobs are important [164], and inspiring sustainability vision is the best tool to explain why their jobs are important [164]. Organizational members are likely to be more satisfied and productive when they perceive the work's meaning and outcome. As a result, stakeholders are also satisfied, enhancing corporate sustainability performance $[73,91]$.

Desirability or ability to inspire in a vision is especially crucial for corporate sustainability since sustainable corporations must demonstrate an organizational capacity to endure difficult economic and social crises [71]. In such crises, it is easy for organizational members to feel demotivated and give up. A desirable or inspiring vision becomes a source of motivation for them during those times to keep doing whatever needs to be done to go through the crises successfully.

Since a shared vision among organizational members is critical to improving corporate sustainability via stakeholder satisfaction [71,73], for a sustainability vision to be shared by organizational members, the sustainability vision must at least contain desirability or ability to inspire [91,151]. Such a desirable sustainability vision motivates organizational members and makes them emotionally committed to attaining sustainability goals, since inspiration is a form of motivation [164]. In addition, an inspiring sustainability vision lifts the organization out of the mundane, by triggering the excitement among organizational members [151]. An inspiring sustainability vision nurtures a more pleasant workplace for organizational members, in turn improving stakeholder satisfaction.

The following proposition for the relationship between the vision attribute of desirability or ability to inspire and corporate sustainability performance was formed.

Proposition 8: taking into the other six attributes and content, sustainability visions declaring an overarching goal that inspires organizational members improve corporate sustainability performance.

I theoretically assert that all seven vision attributes and vision content of stakeholder satisfaction imagery interact to positively influence overall sustainability performance at first through vision communication and shared vision among organizational members and their emotional commitment to it. The vision content of stakeholder satisfaction imagery and the seven vision attributes help to facilitate the vision communication and sharing process by which organizational members turn to be emotionally committed to the sustainability vision, thereby increasing sustainability performance.

Communication of the sustainability vision stimulates organizational members to develop future images in their mind, which in turn motivates them to actualize the sustainability vision [165]. Once their future images are aligned with that of their organization, organizational members are inspired to realize the sustainability vision, enhancing their affective organizational commitment. With this very positive emotional state, they are connected more affectively to the organization [166]. Lending support to this assertion, espousing a vision has been found to associate positively with the affective organizational commitment among organizational members in a wide variety of settings and cultures [167-173].

In addition, I assert that corporate sustainability performance as measured by the triple bottom line outputs leads to improved sustainable wellbeing comprising organizational self-reliance, resilience, and immunity [53]. Therefore, the following propositions were formed.

Proposition 9: the seven vision attributes and content improve vision communication among organizational members.

Proposition 10: vision communication among organizational members increases vision sharing.

Proposition 11: shared vision among organizational members improves their emotional commitment to the vision.

Proposition 12: emotionally committed organizational members act according to the vision to improve corporate sustainability performance.

Proposition 13: corporate sustainability performance comprising the triple bottom line outputs improves the satisfaction of stakeholders. 
Proposition 14: satisfied stakeholders improve sustainable wellbeing constituted by organizational self-reliance, resilience, and immunity.

Finally, as the literature review above indicates reciprocal relationships between organizational success and emotional commitment among organizational members, and between emotional commitment among organizational members and shared vision, the final propositions were formed.

Proposition 15: increased corporate sustainability performance improves organizational commitment among organizational members.

Proposition 16: increased stakeholder satisfaction improves organizational commitment among organizational members.

Proposition 17: improved organizational commitment among organizational members improves vision sharing.

\section{Sustainability Vision Model}

Built upon the original theory of organizational vision [5], the substance of the emerging sustainability vision theory comprises sustainability vision, vision communication, shared vision, emotionally committed organizational members, congruous acts, corporate sustainability performance, satisfied stakeholders, and sustainable wellbeing. Since the emerging theory of sustainability vision is quite intuitive, I employ a graphical representation of the overarching theoretical process as a rhetorical device to elicit epiphanies [42]. Accordingly, a theoretical model on sustainability vision was developed (Figure 1).

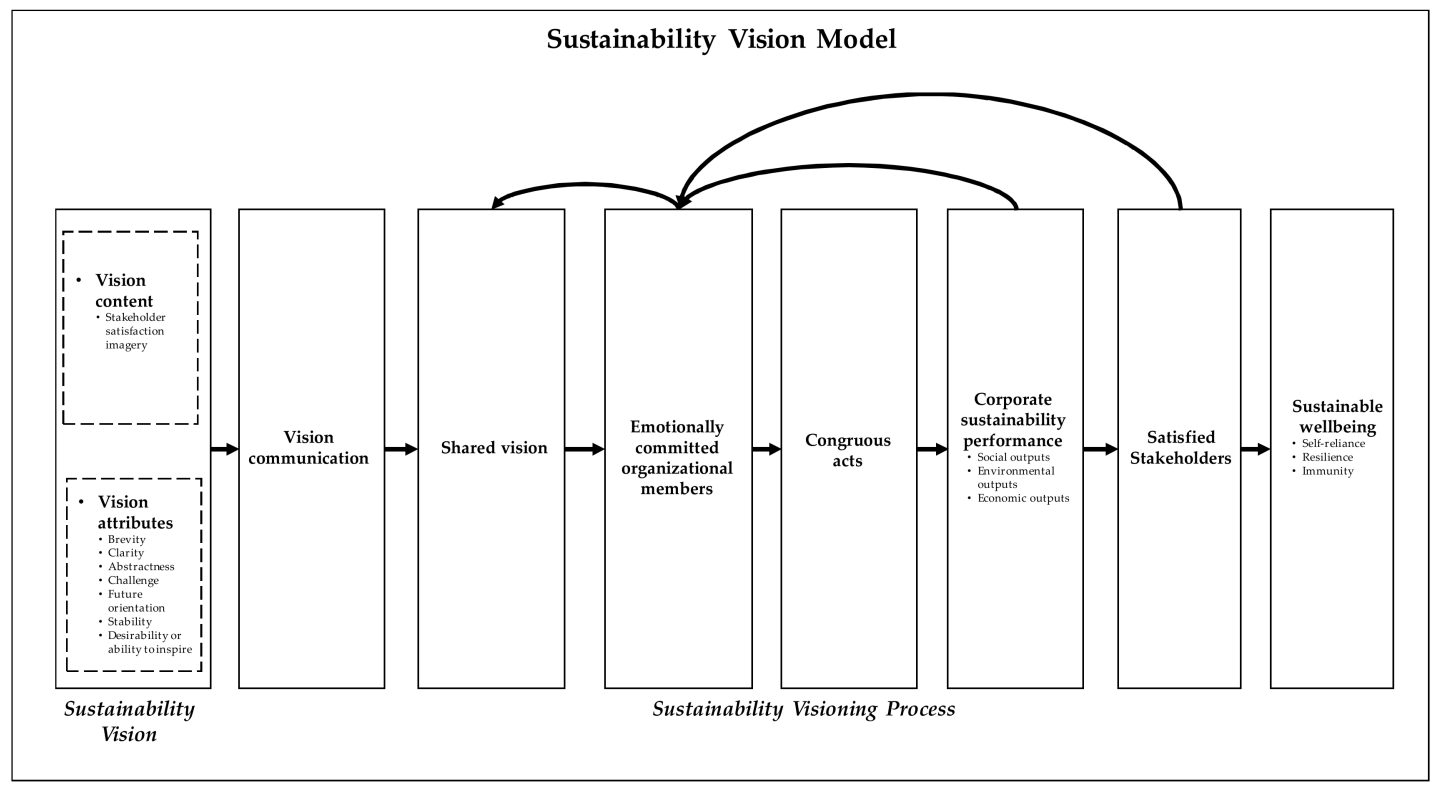

Figure 1. Sustainability vision model.

From left to right, the sustainability vision model asserts that sustainability organizational visions comprise two components: content and attributes. In terms of content, the sustainability visions contain reference to increasing stakeholder satisfaction or stakeholder satisfaction imagery. In terms of vision attributes, the sustainability visions are characterized by brevity, clarity, abstractness, challenge, future orientation, stability, and desirability or ability to inspire. Both content and attributes interact to positively affect vision communication, shared vision, and organizational members in various different ways, the theoretical processes of which are summarized below.

First, the vision content of stakeholder satisfaction imagery reminds organizational members of the importance of satisfying a wide range of stakeholders. Being reminded, they are also satisfied, according to the refined theory. Brevity allows organizational members to understand a brief sustainability vision 
message quickly via massive, continuing, frequent vision communication. Clarity helps to ensure that organizational members are clear about what to be done to foster sustainability, are satisfied in terms of psychological wellbeing because of the stakeholder satisfaction imagery, and experience the self-endorsement of their actions, leading to improved persistence, performance, social functioning, and physical and psychological well-being, all necessary to ensure corporate sustainability.

Abstractness allows organizational members to sense a longer-lasting goal that reflects a longer-lasting organization, which is desirable for them. Abstractness also supports organizational members to form a coherent organization, prevent the formation of too many groups, and to individually creatively interpret the abstract sustainability vision in their own way to attain sustainability goals. Challenge allows organizational members to attribute the extraordinary sustainability vision to the leader. Being challenged, they are always intrinsically motivated to carry on, despite difficulties, leading to corporate perseverance behavior, and at the same time, raising their self-esteem in their effort to realize the sustainability vision. Future orientation reinforces organizational members through a long-term perspective. Future-oriented, they are inspired by and committed to a future view that is clearly better for the organization, themselves, and the society. Avoiding short-termism, they are allowed for the process of careful, reasonable decision-making that involves considering long-term and short-term consequences on the organization and its stakeholders. With a stable sustainability vision, organizational members are not confused while executing sustainability strategies and plans. Stability also allows them to feel that a leader really stands behind the sustainability vision, and encourages organizational members to integrate sustainability into their daily operations.

Finally, desirability or ability to inspire induces organizational members to work toward the sustainability vision. They are invigorated by the enjoyment of the activity they do and feel a clear sense of personal growth, belonging, societal contribution, and health. With desirability, they grasp their work's meaning and outcome and are affectively committed to the sustainability vision.

With the seven attributes and content that facilitate vision sharing, organizational members share and are emotionally committed to the vision. When they are committed to the sustainability vision, they act accordingly to improve corporate sustainability performance, as measured by the triple bottom line outputs. The improved sustainability performance then satisfies stakeholders, whose satisfaction improves sustainable well-being as measured by self-reliance, resilience, and immunity.

In terms of the reciprocal relationships, improved stakeholder satisfaction and triple bottom line outputs in turn enhance emotional commitment among organizational members, who in turn enhance vision sharing in their organization.

\section{Future Research Directions}

Clearly, research is needed to explore the 17 propositions. One critical area to explore is whether and how visions characterized by brevity, clarity, abstractness, challenge, future orientation, stability, and desirability or ability to inspire and containing reference to stakeholder satisfaction imagery are associated with improved corporate sustainability performance and sustainable wellbeing via vision communication, shared vision, emotionally committed organizational members, triple bottom line outputs, and stakeholder satisfaction compared to visions without these characteristics, across different organizational types, sizes and industries. This area of research is a significant contribution to the corporate sustainability field, since there has been hardly any reported research in this specific area.

More specifically, future research may examine and explore the reciprocal relationships between corporate sustainability performance and emotional commitment among organizational members, between stakeholder satisfaction and emotional commitment among organizational members, and between emotional commitment among organizational members and sustainability vision sharing. Findings from this future research will improve our limited knowledge and understanding about these relationships.

Scholars may also explore the process by which each attribute as well as the imagery of stakeholder satisfaction positively affects corporate sustainability performance and sustainable wellbeing. How the 
seven attributes and content interact to create such an impact is also a subject for further investigation. Of equivalent interest is to examine the relative importance between the seven attributes and content, and among the attributes and content. Findings from future research will contribute to the limited knowledge and understanding on vision attributes and content, and will eventually inform further refinement of the sustainability vision theory. By means of repeating research systematically, scholars are allowed to compare and contrast findings from several focal areas [174]. The results from future research will lead to future advancement of the sustainability vision theory and assist in defining its boundary.

\section{Practical Implications}

Although more research is needed into identifying attributes and content of effective sustainability visions, as good theory is practical, the emergent theory of sustainability vision offers some important practical implications.

First, a sustainability vision should be shared throughout the organization via vision communication. In particular, visions that are brief, clear, future-oriented, stable, challenging, abstract, and desirable with content about increasing stakeholder satisfaction are easier to communicate frequently and effectively. With empirical support, they tend to result in better sustainability performance than visions without these attributes and content. Some recommendations for crafting a sustainability vision statement are discussed below.

An effective sustainability vision should contain reference to increasing the satisfaction of stakeholders, including owners/shareholders, customers, organizational members, the environment, and surrounding communities. Since vision must be concise, often the word "society" already includes this wide range of stakeholders. The vision should contain approximately 11-22 words, and point directly at an overarching goal to be achieved. More specifically, this overarching goal must not be likely to be changed by environmental change. The overarching goal also must not be an easy one-time goal that can be met and then the vision is discarded. It should include all organizational interests so that it is appealing to all members of the organization. The vision must include a degree of challenge, stretch, or difficulty (e.g., to attain a national, regional, or international status) to be a source of motivation among organizational members. Finally, since a vision is about a desirable future state, it must offer a long-term, desirable view of the organization.

Sustainability visions containing these attributes and content are expected to result in higher corporate sustainability performance at first through vision communication and emotionally committed members of the organization than those without. In addition, in the long run, improvements in sustainable wellbeing as measured by self-reliance, resilience, and immunity can be expected.

To demonstrate the theory's practicality, an example of a sustainability vision statement that meets these characteristics is below:

"To be the leading socially responsible instant foods provider in the world through stakeholder partnership."

The vision statement is brief because it contains approximately 15 words. It is also clear because it points directly at an overarching goal of being "the leading socially responsible instant foods provider in the world". This clear and concise vision statement allows organizational members to grasp the vision immediately, the start of the vision sharing process in the organization.

The vision or overarching goal is clearly not a one-time, specific goal that can be achieved, and then discarded. Being abstract, the overarching goal needs to be translated into smaller, specific goals inclusive to all organizational interests. Although organizational members may be from different functions and pursue different specific goals, the achievement of these smaller goals together will help to integrate sustainability into its entire operation and to achieve the overarching goal of being "the leading socially responsible instant foods provider in the world".

The overarching goal is very challenging since it aims to be the (only) leading instant foods provider in the world. If the vision is developed by involving organizational members, it suggests a realistic 
degree of discrepancy between the present and the envisioned future. By involving organizational members, the overarching goal is also desirable or inspiring, as it must appeal directly to organizational members. "To be the leading socially responsible instant foods provider in the world" is clearly future-oriented and unlikely to be affected by any environmental change. Such a challenging, desirable, and stable vision will continue to appeal to organizational members' values, therefore intrinsically motivating them, particularly in difficult times.

In terms of content, the vision statement contains the words "socially responsible" and "through stakeholder partnership". Indeed, it contains imagery about satisfying owners/shareholders, organizational members, customers, the society, and the environment. The vision content always reminds all organizational members that they do not exist simply to maximize short-term wealth at any cost, but have to be responsible for the society as well. Other example vision statements that meet the vision attributes and content are shown in Table 2.

Table 2. Example vision statements.

\begin{tabular}{|c|c|}
\hline No. & Example Vision Statement \\
\hline 1 & To become a world leader at connecting people to wildlife and conservation \\
\hline 2 & $\begin{array}{c}\text { To be a European leader in banking and insurance always adhering to the UN Global } \\
\text { Compact principles. }\end{array}$ \\
\hline 3 & $\begin{array}{l}\text { To be the world's most valued company to patients, customers, colleagues, investors, } \\
\text { business partners, and the communities where we work and live. }\end{array}$ \\
\hline 4 & $\begin{array}{l}\text { To be a regional market leader with a commitment to business growth along with } \\
\text { contribution to the sustainable advancement of ASEAN }\end{array}$ \\
\hline
\end{tabular}

Having a sustainability vision meeting the above criteria is only a jump-start. To maximize corporate sustainability performance and sustainable wellbeing, the sustainability vision needs to be communicated among organizational members wherever and whenever possible so that they can interpret the vision in their own way and use it to guide their daily operation. Organizational members should also be continuously motivated and empowered to act upon the sustainability vision, especially critical when they are enduring a social or economic crisis or any other difficult time. Lastly, organizational systems must be designed to support the members to attain the sustainability vision by aligning the systems with the sustainability vision.

Funding: This research received no funding support.

Conflicts of Interest: The author declares no conflict of interest.

\section{References}

1. Collins, J.C.; Porras, J.I. Built to Last, older ed.; Century Business: London, UK, 1996.

2. Ireland, D.; Hitt, M.A. Mission statements: Importance, challenge. Bus. Horiz. 1992, 35, 34. [CrossRef]

3. Baumgartner, R.J. Managing corporate sustainability and CSR: A conceptual framework combining values, strategies and instruments contributing to sustainable development. Corp. Soc. Responsib. Environ. Mgmt. 2014, 21, 258-271. [CrossRef]

4. Paraschiv, D.M.; Nemoianu, E.L.; Langa, C.A.; Szabó, T. Eco-innovation, responsible leadership and organizational change for corporate sustainability. Amfiteatru Econ. 2012, 14, 404-419.

5. Kantabutra, S. Toward a behavioral theory of vision in organizational settings. Leadersh. Organ. Dev. J. 2009, 30, 319-337. [CrossRef]

6. D'Souza, D.E.; Clower, T.L.; Nimon, K.F.; Oldmixon, E.A.; van Tassel, F.S. Developing a mission statement for a faculty senate. Plan. High. Educ. 2011, 39, 15-24.

7. Ganpat, W.; Harder, A.; Moore, A. Envisioning the future of extension and advisory services in the Caribbean. J. Int. Agric. Ext. Educ. 2014, 21, 19-31. [CrossRef]

8. Gracey, S. Leadership in Policing: Serving Others to Serve Society. Ph.D. Thesis, Durham University Business School, Durham, UK, 2019. Available online: http://etheses.dur.ac.uk/13209/ (accessed on 1 December 2019). 
9. Haque, M.; TitiAmayah, A.; Liu, L. The role of vision in organizational readiness for change and growth. Leadersh. Organ. Dev. J. 2016, 37, 983-999. [CrossRef]

10. Jing, F.F.; Avery, G.C.; Bergsteiner, H. Enhancing performance in small professional firms through vision communication and sharing. Asia Pac. J. Manag. 2014, 31, 599-620. [CrossRef]

11. Jing, F.F.; Avery, G.C.; Bergsteiner, H. Leadership variables and business performance: Mediating and interaction effects. J. Leadersh. Organ. Stud. 2019, 26,1-18. [CrossRef]

12. Kopaneva, I. Employee Constructions of Organizational Mission and Vision. Ph.D. Thesis, The Edward R. Murrow College of Communication, Washington State University, Pullman, WA, USA, 2013. Unpublished.

13. Kopaneva, I.; Sias, P.M. Lost in translation: Employee and organizational constructions of mission and vision. Manag. Commun. Q. 2015, 29, 358-384. [CrossRef]

14. Kukkurainen, M.L.; Suominen, T.; Rankinen, S.; Härkönen, E.; Kuokkanen, L. Organizational vision: Experience at the unit level. J. Nurs. Manag. 2012, 20, 868-876. [CrossRef] [PubMed]

15. Mjimba, V. Main-streaming the climate change and green growth agenda into development visions: A narrative from selected sub-Sahara African countries. Int. J. Afr. Renaiss. Stud. Multi-Inter- Transdiscipl. 2014, 9, 95-112. [CrossRef]

16. Mohd Adnan, S.; Valliappan, R. Communicating shared vision and leadership styles towards enhancing performance. Int. J. Product. Perform. Manag. 2019, 68, 1042-1056. [CrossRef]

17. Myrick, K.A. Vision Matters: Vision Content and Organizational Performance. Ph.D. Thesis, Saint Mary's University, Halifax, NS, Canada, 2017.

18. O'Connell, D.; Hickerson, K.; Pillutla, A. Organizational visioning: An integrative review. Group Organ. Manag. 2011, 36, 103-125. [CrossRef]

19. O'Donnell, M.; Ruth-Sahd, L.; Mayfield, C. An expanded holistic model of healthy workplace practices. Int. J. Organ. Anal. 2019, 27, 1542-1561. [CrossRef]

20. Peterlin, J.; Dimovski, V.; Colnar, S.; Grah, B. Professional Development of Business Students: Vision Creating. In Proceedings of the ENTRENOVA-ENTerprise REsearch InNOVAtion Conference, Dubrovnik, Croatia, 7-9 September 2017; IRENET—Society for Advancing Innovation and Research in Economy: Zagreb, Croatia, 2017; pp. 288-295.

21. Rahimnia, F.; Moghadasian, M.; Mashreghi, E. Application of grey theory approach to evaluation of organizational vision. Grey Syst. Theory Appl. 2011, 1, 33-46. [CrossRef]

22. Sethi, A.; Adhikari, B. Impact of communicating "vision" on organizational communication effectiveness. Int. J. Mark. Bus. Commun. 2012, 1, 43-48.

23. Hallinger, P.; Suriyankietkaew, S. Science mapping of the knowledge base on Sustainable Leadership, 1990-2018. Sustainability 2018, 10, 4846. [CrossRef]

24. Ketprapakorn, N. Toward an Asian corporate sustainability model: An integrative review. J. Clean. Prod. 2019, 239, 117995. [CrossRef]

25. Nanus, B. Visionary Leadership: Creating a Compelling Sense of Direction for Your Organization; Jossey-Bass: San Francisco, CA, USA, 1992.

26. Epstein, M.J.; Buhovac, A.R. Solving the sustainability implementation challenge. Organ. Dyn. 2010, 39, 306-315. [CrossRef]

27. Howard-Grenville, J.; Buckle, S.J.; Hoskins, B.J.; George, G. From the editors: Climate change and management. Acad. Manag. J. 2014, 57, 615-623. [CrossRef]

28. Lewin, K. Psychology and the process of group living. J. Soc. Psychol. 1943, 17, 113-131. [CrossRef]

29. Kilduff, M. Editor's comments: Publishing theory. Acad. Manag. Rev. 2006, 31, 252-255. [CrossRef]

30. Corley, K.; Gioia, D. Building theory about theory building: What constitutes a theoretical contribution? Acad. Manag. Rev. 2011, 36, 12-32. [CrossRef]

31. Mintzberg, H. Developing theory about the development of theory. In Great Minds in Management: The Process of Theory Development; Smith, K.G., Hitt, M.A., Eds.; Oxford University Press: Oxford, UK, 2005; pp. 355-372.

32. Kantabutra, S.; Avery, G. The power of vision: Statements that resonate. J. Bus. Strategy 2010, 31, 37-45. [CrossRef]

33. Lynham, S.A. Theory building in the human resource development profession. Hum. Resour. Dev. Q. 2000, 11, 159-178. [CrossRef]

34. Dubin, R. Theory building in applied areas. In Handbook of Industrial and Organizational Psychology; Dunnette, M.D., Ed.; Rand McNally: Chicago, IL, USA, 1976; pp. 17-39. 
35. Marsick, V.J. Altering the paradigm for theory-building in human resource development. Hum. Resour. Dev. 1990, 1, 5-24. [CrossRef]

36. Eisenhardt, K.M.; Graebner, M.E. Theory building from cases: Opportunities and challenges. Acad. Manag. J. 2007, 50, 25-32. [CrossRef]

37. Gall, M.D.; Borg, W.R.; Gall, J.P. Education Research, an Introduction; Longman Publishers: New York, NY, USA, 1996.

38. Kaplan, A. The Conduct of Inquiry; Chandler: San Francisco, CA, USA, 1964.

39. Swanson, R.A. HRD research: Don't go to work without it. In Human Resource Development Handbook: Linking Research and Practice; Swanson, R.A., Holton, E.F., III, Eds.; Berrett-Koehler: San Francisco, CA, USA, 1997; pp. 3-20.

40. Kuhn, T. The Structure of Scientific Revolutions, 2nd ed.; Chicago University Press: Chicago, IL, USA, 1970.

41. Swanson, R.A.; Lynham, S.A.; Ruona, W.E.A.; Torraco, R.J. Theory building research in HRD—Pushing the envelope! In Proceedings of the Academy of Human Resource Development 2000 Annual Conference, Raleigh-Durham, NC, USA, 8-12 March 2000; Kuchinke, P., Ed.; Academy of Human Resource Development: Baton Rouge, LA, USA, 2000.

42. DiMaggio, P.L. Comments on what theory is not. Adm. Sci. Q. 1995, 40, 291-397. [CrossRef]

43. Laughlin, R. Empirical research in accounting: Alternative approaches and a case of middle range thinking. Account. Audit. Account. J. 1995, 8, 63-87. [CrossRef]

44. Parker, L.D.; Roffey, B.H. Back to the drawing board: Revisiting grounded theory and the everyday accountant's and manager's reality. Account. Audit. Account. J. 1997, 10, 212-247. [CrossRef]

45. Whetten, D.A. What constitutes a theoretical contribution? Acad. Manag. Rev. 1989, 14, 490-495. [CrossRef]

46. Weick, K. Cognitive processes in organizations. In Research in Organizational Behavior; Staw, B., Ed.; JAI: Greenwich, CT, USA, 1989; Volume 1, pp. 41-74.

47. Beard, M.T. Theory development in a new millennium. J. Theory Constr. Test. 2000, 4, 5-7.

48. Kaplan, A. The Conduct of Inquiry: Methodology for Behavioral Science; Transaction: New Brunswick, NJ, USA, 1998.

49. Ashrafia, M.; Adams, M.; Walkera, T.R.; Magnan, G. How corporate social responsibility can be integrated into corporate sustainability: A theoretical review of their relationships. Int. J. Sustain. Dev. World Ecol. 2018, 25, 672-682. [CrossRef]

50. Swarnapali, R. Corporate sustainability: A literature review. J. Account. Res. Educ. 2017, 1, 1-15.

51. Wilson, M. Corporate Sustainability: What is it and where does it come from? Ivey Bus. J. 2003, 67, 1-5.

52. Elkington, J. Accounting for the triple bottom line. Meas. Bus. Excell. 1998, 2, 18-22. [CrossRef]

53. Avery, G.C.; Bergsteiner, H. Sufficiency Thinking; Allen \& Unwin: Crows Nest, Australia, 2016.

54. Holyoak, K.J.; Thagard, P. The analogical mind. Am. Psychol. 1997, 52, 35-44. [CrossRef]

55. Largan-Fox, J.; Code, S. Team mental models: Technique, methods, and analytical approaches. Hum. Factors 2000, 42, 242-271. [CrossRef]

56. Rouse, R.B.; Cannon-Bowers, J.A.; Salas, E. The role of mental models in team performance in complex systems. IEEE Trans. Syst. Man Cybern. 1992, 22, 1290-1308. [CrossRef]

57. Mumford, M.D.; Strange, J.M. Vision and Mental Models: The Case of Charismatic and Ideological Leadership. In Transformational and Charismatic Leadership: The Road Ahead 10th Anniversary Edition; Emerald Group Publishing: Bingley, UK, 2015; pp. 125-158.

58. Castro, R.; Lohmann, G. Airport branding: Content analysis of vision statements. Res. Transp. Bus. Manag. 2014, 10, 4-14. [CrossRef]

59. Baum, I.R.; Locke, E.A.; Kirkpatrick, S.A. A longitudinal study of the relation of vision and vision communication to venture growth in entrepreneurial firms. J. Appl. Psychol. 1998, 83, 43-54. [CrossRef]

60. Levin, M.L. Vision revisited. J. Appl. Behav. Sci. 2000, 36, 91-107. [CrossRef]

61. Kaplan, R.S.; Norton, D.P. The balanced scorecard-Measures that drive performance. Harv. Bus. Rev. 1992, 70, 71-80. [PubMed]

62. Avery, G.C. Understanding Leadership; Sage: London, UK, 2004.

63. Bunker, B.B.; Alban, B.T. The Handbook of Large Group Methods: Creating Systemic Change in Organizations and Communities; Jossey-Bass: San Francisco, CA, USA, 2006.

64. O'Brien, F.; Meadows, M. Exploring the current practice of visioning: Case studies from the UK financial services sector. Manag. Decis. 2003, 41, 488-497. [CrossRef] 
65. Peel, D.; Lloyd, G. City-visions: Visioning and delivering Scotland's economic future. Local Econ. 2005, 20, 40-52. [CrossRef]

66. Berson, Y.; Waldman, D.A.; Pearce, C.L. Enhancing our understanding of vision in organizations: Toward an integration of leader and follower processes. Organ. Psychol. Rev. 2016, 6, 171-191. [CrossRef]

67. Senge, P.M. The Fifth Discipline: The Art \& Practice of the Learning Organization; Currency Doubleday: New York, NY, USA, 1990.

68. Kantabutra, S.; Avery, G.C. Follower effects in the visionary leadership process. J. Bus. Econ. Res. 2006, 4, 57-66. [CrossRef]

69. March, J.G.; Olsen, J.P. Ambiguity and Choice in Organizations; Universitetsforlaget: Bergen, Norway, 1979.

70. Luhmann, N. Organization and Decision; Cambridge University Press: Cambridge, UK, 2018.

71. Avery, G.C. Leadership for Sustainable Futures; Edward Elgar: Northampton, MA, USA, 2005.

72. Avery, G.C.; Bergsteiner, H. Honeybees \& Locusts: The Business Case for Sustainable Leadership; Allen \& Unwin: Crows Nest, Australia, 2010.

73. Kantabutra, S. Achieving corporate Sustainability: Toward a practical theory. Sustainability 2019, 11, 4155. [CrossRef]

74. Bass, B.M.; Avolio, B.J. Transformational leadership: A response to critiques. In Leadership Theory and Research: Perspectives and Directions (49-80); Chemers, M.M., Ayman, R., Eds.; Academic Press: San Diego, CA, USA, 1993.

75. House, R.J.; Shamir, B. Toward the integration of transformational, charismatic and visionary theories of leadership. In Leadership Theory and Research: Perspectives and Directions (81-107); Chemers, M., Ayman, R., Eds.; Academic Press: San Diego, CA, USA, 1993.

76. Awamleh, R.; Gardner, W. Perceptions of leader charisma and effectiveness: The effects of vision content, delivery, and organizational performance. Leadersh. Q. 1999, 10, 345-373. [CrossRef]

77. Tvorik, S.J.; McGivern, M.H. Determinants of organizational performance. Manag. Decis. 1997, 35, 417-435.

78. Kouzes, J.M.; Posner, B.Z. The Leadership Challenge: How to Get Extraordinary Things Done in Organizations; Jossey-Bass: San Francisco, CA, USA, 1987.

79. Larwood, L.; Falbe, C.M.; Kriger, M.R.; Miesling, P. Structure and meaning of organizational vision. Acad. Manag. J. 1995, 38, 740-769.

80. Van der Helm, R. The vision phenomenon: Towards a theoretical underpinning of vision of the future and the process of envisioning. Futures 2009, 41, 96-104. [CrossRef]

81. Coleman, J. Six Components of a Great Corporate Culture. Harvard Business Review Blog Network. 2013. Available online: http://blogs.hbr.org/cs/2013/05/six_components_of_culture.html (accessed on 2 September 2019).

82. Schnebel, E. Values in decision-making processes: Systematic structures of J. Habermas and N. Luhmann for the appreciation of responsibility in leadership. J. Bus. Ethics 2000, 27, 79-88. [CrossRef]

83. Christensen, L.T.; Morsing, M.; Thyssen, O. CSR as aspirational talk. Organization 2013, 20, $372-393$. [CrossRef]

84. Bromley, P.; Powell, W.W. From smoke and mirrors to walking the talk: Decoupling in the contemporary world. Acad. Manag. Ann. 2012, 6, 483-530. [CrossRef]

85. Meyer, J.W.; Rowan, B. Institutional organizations: Structure as myth and ceremony. Am. J. Sociol. 1977, 83, 340-363. [CrossRef]

86. Graafland, J.; Smid, H. Decoupling Among CSR Policies, Programs, and Impacts: An Empirical Study. Bus. Soc. 2016, 58, 231-267. [CrossRef]

87. Foster, R.; Akdere, M. Effective organizational vision: Implications for human resource development. J. Eur. Ind. Train. 2007, 31, 100-111. [CrossRef]

88. Rampersad, H.K. Total Quality Management: An Executive Guide to Continuous Improvement; Springer: Heidelberg, Germany, 2001.

89. Ford, J.D.; Pasmore, W.A. Vision: Friend or foe during change? J. Appl. Behav. Sci. 2006, 42, 172-176. [CrossRef]

90. Ketprapakorn, N.; Kantabutra, S. Culture development for sustainable SMEs: Toward a behavioral theory. Sustainability 2019, 11, 2629. [CrossRef]

91. Ketprapakorn, N.; Kantabutra, S. Sustainable social enterprise model: Relationships and consequences. Sustainability 2019, 11, 3772. [CrossRef] 
92. Kantabutra, S. Relating vision-based leadership to sustainable business performance: A Thai perspective. Leadersh. Rev. 2006, 6, 37-53.

93. Dupree, M. Leadership Jazz; Doubleday: New York, NY, USA, 1992.

94. Galbraith, J.R.; Lawler, E.E., III. Associates. Organizing for the Future; Jossey-Bass: San Francisco, CA, USA, 1993.

95. Nadler, G.; Hibino, S. Breakthrough Thinking; Prima: Rocklin, CA, USA, 1990.

96. Oakley, E.; Krug, D. Enlightened Leadership; Simon and Schuster: New York, NY, USA, 1993.

97. Wilkens, A.L. Developing Corporate Character; Jossey-Bass: San Francisco, CA, USA, 1989.

98. Rafferty, A.F.; Griffin, M.A. Dimensions of transformational leadership: Conceptual and empirical extensions. Leadersh. Q. 2004, 15, 329-354. [CrossRef]

99. Westley, F.; Mintzberg, H. Visionary leadership and strategic management. Strateg. Manag. J. 1989, 10, 17-32. [CrossRef]

100. Baum, J.R.; Locke, E.A. The relationship of entrepreneurial traits, skill, and motivation to subsequent venture growth. J. Appl. Psychol. 2004, 89, 587-598. [CrossRef]

101. Kantabutra, S.; Vimolratana, P. Vision-based leadership: Relationships and consequences in Thai and Australian retail stores. Asia-Pac. J. Bus. Adm. 2009, 1, 165-188. [CrossRef]

102. Pearson, A.E. Six basics for general managers. Harv. Bus. Rev. 1989, 67, 94-101.

103. Locke, E.A.; Kirkpatrick, S.; Wheeler, J.K.; Schneider, J.; Niles, K.; Goldstein, H.; Welsh, K.; Chah, D.O. The Essence of Leadership; Lexington Books: New York, NY, USA, 1991.

104. World Commission on Environment and Development. Our Common Future; Oxford University Press: Oxford, UK, 1987.

105. Ryan, R.M.; Deci, E.L. Self-Determination Theory: Basic Psychological Needs in Motivation, Development, and Wellness; Guilford Publishing: New York, NY, USA, 2017.

106. Phillips, R.; Freeman, R.E.; Wicks, A.C. What stakeholder theory is not. Bus. Ethics Q. 2003, 13, 479-502. [CrossRef]

107. Shirey, M.R. Lewin's theory of planned change as a strategic resource. J. Nurs. Adm. 2013, 43, 69-72. [CrossRef]

108. Nonaka, I.A. Dynamic theory of organizational knowledge creation. Organ. Sci. 1994, 5, 14-37. [CrossRef]

109. Barney, J. Firm resources and sustained competitive advantage. J. Manag. 1991, 17, 99-120. [CrossRef]

110. Eisenhardt, K.; Martin, J. Dynamic capabilities: What are they? Strateg. Manag. J. 2000, 21, $1105-1121$. [CrossRef]

111. Helfat, C.E.; Peteraf, M.A. The dynamic resource-based view: Capability lifecycles. Strateg. Manag. J. 2003, 24, 997-1010. [CrossRef]

112. Tzortzaki, A.M.; Mihiotis, A. A review of knowledge management theory and future directions. Knowl. Process. Manag. 2014, 21, 29-41. [CrossRef]

113. De Hoogh, A.H.B.; Den Hartog, D.N. Ethical and despotic leadership, relationships with leader's social responsibility, top management team effectiveness and subordinates' optimism: A multi-method study. Leadersh. Q. 2008, 19, 297-311. [CrossRef]

114. Bengtsson, M.; Kock, S. Cooperation and competition in relationships between competitors in business networks. J. Bus. Ind. Mark. 1999, 14, 178-194. [CrossRef]

115. Emec, S.; Bilge, P.; Seliger, G. Design of production systems with hybrid energy and water generation for sustainable value creation. Clean Technol. Environ. Policy 2015, 17, 1807-1829. [CrossRef]

116. Luo, Y. A coopetition perspective of global competition. J. World Bus. 2007, 42, 129-144. [CrossRef]

117. Christ, K.L.; Burritt, R.L.; Varsei, M. Coopetition as a potential strategy for corporate sustainability. Bus. Strat. Environ. 2017, 26, 1029-1040. [CrossRef]

118. Gnyawali, D.R.; Park, B.-J. Co-opetition and technological innovation in small and medium-sized enterprises: A multilevel conceptual model. J. Small Bus. Manag. 2009, 47, 308-330. [CrossRef]

119. Brenner, S.N. The stakeholder theory of the firm and organizational decision making. Proc. Int. Assoc. Bus. Soc. 1993, 4, 405-416. [CrossRef]

120. Greenwood, R.; Oliver, C.; Lawrence, T.B.; Meyer, R.E. (Eds.) The Sage Handbook of Organizational Institutionalism; Sage: London, UK, 2017.

121. Brunsson, N. The Organization of Hypocrisy: Talk, Decisions and Actions in Organizations; John Wiley \& Sons: New York, NY, USA, 1989. 
122. Christensen, L.T.; Morsing, M.; Thyssen, O. The polyphony of values and the value of polyphony. J. Commun. Stud. 2015, 8, 15.

123. Daft, R.L. The Leadership Experience; Thomson South-Western: Mason, OH, USA, 2005.

124. Down, C.W.; Conrad, C. A critical incident study of superior-subordinate communication. Presented at the Academy of Management Convention, San Francisco, CA, USA, 8-11 August 1978.

125. Kotter, J.P. Why transformation efforts fail? Harvard Business Review, 1995; May-June, $59-67$.

126. Yukl, G.A. Leadership in Organizations, 4th ed.; Prentice Hall: Englewood Cliffs, NJ, USA, 1998.

127. Witherspoon, P.D. Communicating Leadership: An Organizational Perspective; Allyn and Bacon: Needham, MA, USA, 1997.

128. Heskett, J.L.; Sasser, W.E.; Schlesinger, L.A. The Service Profit Chain: How Leading Companies Link Profit and Growth to Loyalty, Satisfaction, and Value; Free Press: New York, NY, USA, 1997.

129. Conrad, C. Strategic Organizational Communication: An Integrated Perspective; Harcourt Brace Jovanovich College Publishers: Orlando, FL, USA, 1990.

130. Pace, R.W.; Faules, D.F. Organizational Communication, 2nd ed.; Prentice Hall: Englewood Cliffs, NJ, USA, 1989.

131. Bennis, W.G.; Nanus, B. Leaders: The Strategies for Taking Charge; Harper and Row: New York, NY, USA, 1985.

132. Peters, T.J.; Waterman, R.H.J. In Search of Excellence; Warner Books: New York, NY, USA, 1982.

133. Nutt, P.C.; Backoff, R.W. Crafting vision. J. Manag. Inq. 1997, 6, 308-328. [CrossRef]

134. Vansteenkiste, M.; Niemiec, C.; Soenens, B. The development of the five mini-theories of self-determination theory: An historical overview, emerging trends, and future directions. Theor. Perspect. Motiv. Achiev 2010, 16, 105-165.

135. El-Namaki, M. Creating a corporate vision. Long Range Plan. 1992, 25, 25-29. [CrossRef]

136. Rousseau, D.M. Organizational behavior in the new organizational era. Annu. Rev. Psychol. 1997, 48, 515-546. [CrossRef]

137. Rogers, R.; Hunter, J.E. Impact of management by objectives on organizational productivity. J. Appl. Psychol. 1991, 76, 322-336. [CrossRef]

138. Canetti, E. Crows and Power; The Continuum Publishing Corporation: New York, NY, USA, 1960.

139. Tarnow, E. A recipe for mission and vision statements. J. Mark. Pract. Appl. Mark. Sci. 1997, 3, $184-189$. [CrossRef]

140. Messick, D.; Mackie, D. Intergroup relations. Annu. Rev. Psychol. 1989, 40, 45-81. [CrossRef]

141. Freud, S. Group Psychology and The Analysis of the Ego; Norton: New York, NY, USA, 1921.

142. Collins, J.C.; Porras, J.I. Built to Last: Successful Habits of Visionary Companies; Century: London, UK, 1994.

143. Conger, J.A. Charismatic and transformational leadership in organizations: An insider's perspective on these developing streams of research. Leadersh. Q. 1999, 10, 145-179. [CrossRef]

144. Conger, J.A.; Kanungo, R.N. Toward a behavioral theory of charismatic leadership in organizational settings. Acad. Manag. Rev. 1987, 12, 637-647. [CrossRef]

145. Deal, T.E.; Kennedy, A.A. Corporate Cultures; Penguin: London, UK, 1988.

146. Locke, E.A.; Latham, G.P. Goal Setting: A Motivational Technique That Works; Prentice Hall: Englewood Cliffs, NJ, USA, 1984.

147. Hovland, C.I.; Pritzker, H.A. Extent of opinion change as a function of amount change advocated. J. Abnorm. Soc. Psychol. 1957, 54, 257-261. [CrossRef] [PubMed]

148. Petty, R.E.; Cacioppo, J.T. Attitudes and Persuasion: Classic and Contemporary Approaches; Brown: Dubuque, IA, USA, 1981.

149. Gecas, V.; Self, M.A. Social class and self-esteem: Psychological centrality, compensation, and the relative effects of work and home. Soc. Psychol. Q. 1990, 53, 165-173. [CrossRef]

150. Maslow, A.H. A theory of human motivation. Psychol. Rev. 1943, 50, 370-396. [CrossRef]

151. Parikh, J.; Neubauer, F. Corporate visioning. In International Review of Strategic Management; Hussey, D.E., Ed.; Wiley: Chichester, UK, 1993; Volume 4, pp. 105-116.

152. Peters, T.J. Thriving on Chaos: Handbook for a Management Revolution; Harper and Row: New York, NY, USA, 1987.

153. Bass, B.M. Leadership and Performance Beyond Expectations; Free Press: New York, NY, USA, 1985.

154. Kouzes, J.M.; Posner, B.Z. The Leadership Challenge; Jossey-Bass: San Francisco, CA, USA, 2010.

155. Bennis, W.G. The four competencies of leadership. Train. Dev. J. 1984, 28, 14-19. 
156. Conger, J.A.; Kanungo, R.N. Charismatic Leadership: The Elusive Factor in Organizational Effectiveness; Jossey-Bass: San Francisco, CA, USA, 1988.

157. Bass, B.M. Bass and Stogdill's Handbook of Leadership: Theory, Research, and Managerial Applications, 3rd ed.; Free Press: New York, NY, USA, 1990.

158. Kotter, J.P. The Leadership Factor; Free Press: New York, NY, USA, 1988.

159. Morsing, M.; Oswald, D. Sustainable leadership: Management control systems and organizational culture in Novo Nordisk A/S. Corp. Gov. 2009, 9, 83-99. [CrossRef]

160. Quinn, L.; Dalton, M. Leading for Sustainability: Implementing the Tasks of Leadership. Corp. Gov. 2009, 9, 21-38. [CrossRef]

161. D'Amato, A.; Roome, N. Toward an integrated model of leadership for corporate responsibility and sustainable development: A process model of corporate responsibility beyond management innovation. Corp. Gov. Int. J. Bus. Soc. 2009, 9, 421-434. [CrossRef]

162. Bryman, A. Charisma and Leadership in Organizations; Sage: London, UK, 1992.

163. Kasser, T.; Ryan, R.M. Further examining the American dream: Differential correlates of intrinsic and extrinsic goals. Personal. Soc. Psychol. Bull. 1996, 22, 280-287. [CrossRef]

164. Morden, T. Leadership as vision. Manag. Decis. 1997, 35, 668-676. [CrossRef]

165. Stam, D.A. Managing Dreams and Ambitions: A Psychological Analysis of Vision Communication. Ph.D. Thesis, Erasmus Research Institute of Management, Erasmus University Rotterdam, Rotterdam, The Netherlands, 2008.

166. Eisenberger, R.; Armeli, S.; Rexwinkel, B.; Lynch, P.D.; Rhoades, L. Reciprocation of perceived organizational support. J. Appl. Psychol. 2001, 86, 42-51. [CrossRef] [PubMed]

167. Avolio, B.J. Full Leadership Development: Building the Vital Forces in Organizations; Sage: Thousand Oaks, CA, USA, 1999.

168. Bass, B.M. Transformational Leadership: Industry, Military E Educational Impact; Erlbaum: Mahwah, NJ, USA, 1998.

169. Erkutlu, H. The impact of transformational leadership on organizational and leadership effectiveness: The Turkish case. J. Manag. Dev. 2008, 27, 708-726. [CrossRef]

170. Kantabutra, S.; Rungruang, P. Perceived vision-based leadership effects on staff satisfaction and commitment at a Thai energy provider. Asia-Pac. J. Bus. Adm. 2013, 5, 157-178. [CrossRef]

171. Marmaya, N.H.; Hitam, M.; Torsiman, N.; Balakrishnan, B. Employees' perceptions of Malaysian managers' leadership styles and organizational commitment. Afr. J. Bus. Manag. 2011, 5, 1584-1588.

172. Riaz, T.; Akram, M.U.; Ijaz, H. Impact of transformational leadership style on affective employees' commitment: An empirical study of banking sector in Islamabad (Pakistan). J. Commer. 2011, 3, 43-51.

173. Walumbwa, F.O.; Orwa, B.; Wang, P.; Lawler, J.J. Transformational leadership, organizational commitment, and job satisfaction: A comparative study of Kenyan and U.S. financial firms. Hum. Resour. Dev. Q. 2005, 16, 235-256. [CrossRef]

174. Tsang, E.; Kwan, K. Replication and theory development in organizational science: A critical realist perspective. Acad. Manag. Rev. 1999, 24, 759-780. [CrossRef]

(C) 2020 by the author. Licensee MDPI, Basel, Switzerland. This article is an open access article distributed under the terms and conditions of the Creative Commons Attribution (CC BY) license (http://creativecommons.org/licenses/by/4.0/). 